\title{
Tipos de solo e sua importância para povos indígenas: uma experiência no ensino regular
}

A compreensão sobre os diferentes tipos de solo e a sua importância para todos é condição fundamental para a conscientização e o desenvolvimento das práticas de sustentabilidade. Este texto tem como objetivo explanar uma experiência didático-pedagógica em que se trabalhou os conceitos sobre os tipos de solo e sua importância para o ser humano, em especial, para os povos os indígenas, através de uma oficina teórico-prática para alunos não indígenas no $4^{\circ}$ ano em uma escola da rede pública, na cidade de Campo Formoso (Poços), a fim de incentivar aos mesmos a valorizar e fazer um bom uso do solo. A oficina foi realizada po meio de conceitos orais, práticos e expositivos, no qual, de imediato foi possível perceber uma boa assimilação por todos da classe em relação aos conceitos aplicados. É possível concluir que um trabalho educacional voltado para o estudo do solo e sua importância na cultura indígena, mobiliza elementos didáticos para um fazer pedagógico abrangente, contextualizado e de cunho ambiental.

Palavras-chave: Tipos de solo; Indígenas; Educação ambiental.

\section{Soil types and their importance for indigenous peoples: an experience in regular education}

\begin{abstract}
Understanding the different types of soil and their importance for everyone is a fundamental condition for raising awareness and developing sustainability practices. This text aims to explain a didactic-pedagogical experience in which the concepts of soil types and their importance for human beings, especially for indigenous peoples, were worked through a theoretical-practical workshop for non-indigenous students in the 4th year at a public school, in the city of Campo Formoso (Poços), in order to encourage them to value and make good use of the soil. The workshop was carried out through oral, practical and expository concepts, in which, immediately, it was possible to perceive a good assimilation by all of the class in relation to the applied concepts. It is possible to conclude that an educational work focused on the study of the soil and its importance in indigenous culture, mobilizes didactic elements for a comprehensive, contextualized and environmental nature pedagogical practice.
\end{abstract}

Keywords: Soil types; Indigenous people; Environmental education.

Topic: Desenvolvimento, Sustentabilidade e Meio Ambiente

Reviewed anonymously in the process of blind peer
Received: 09/09/2019

Approved: 10/01/2020
Liliane Martins dos Santos Instituto Federal Baiano, Brasil http://lattes.cnpq.br/2530169259032429 http://orcid.org/0000-0001-8811-6654 Iylianeribeiro1@gmail.com

Almires Martins Freitas

Instituto Federal Baiano, Brasil http://lattes.cnpq.br/3365862542382229

http://orcid.org/0000-0003-2590-7138

irismartins240@gmail.com

Ananda Raquel dos Santos Batista (ic

Instituto Federal Baiano, Brasil

http://lattes.cnpq.br/9426701352465802

http://orcid.org/0000-0002-7994-9854

anandaraquel97@gmail.com
Tássia Caroline Santos de Carvalho id

Instituto Federal Baiano, Brasil

http://lattes.cnpq.br/1129292948500099

http://orcid.org/0000-0001-8421-4046

tassiacarolinee123@gmail.com

Marcos Oliveira Santos

Instituto Federal Baiano, Brasil

http://lattes.cnpq.br/3608399669010480

http://orcid.org/0000-0001-9825-0478

marcos.oliveira@ifbaiano.edu.br
Referencing this:

SANTOS, L. M.; FREITAS, A. M.; BATISTA, A. R. S.; CARVALHO, T. C. S.; SANTOS, M. O.. Tipos de solo e sua importância para povos indígenas: uma experiência no ensino regular. Agrariae Liber, v.2, n.1, p.1-5, 2020. DOI: http://doi.org/10.6008/CBPC2674-6476.2020.001.0001 


\section{INTRODUÇÃO}

O presente relato discorre sobre as ações que foram desenvolvidas na escola pública do munícipio de Campo Formoso, no Povoado de Poços/BA. Este trabalho foi baseado na aplicação de uma oficina no ensino regular com a temática 'tipos de solo e sua importância para os indígenas", estabelecendo uma relação entre as ciências naturais com as práticas de povos indígenas, dentro do contexto de formação sobre a educação ambiental. Foi requisito avaliativo do componente curricular Pesquisa e Práticas Pedagógicas III: Educação e Diversidades da Licenciatura em Ciências Agrárias do Instituto Federal Baiano campus Senhor do Bonfim/BA.

Parte-se da afirmação de Lima et al. (2017) de que, "o solo é um componente importante dos sistemas naturais e dos sistemas que sofreram com a ação humana. Porém, muitas vezes, este elemento não recebe a atenção necessária ou é ignorado, o que leva a problemas ambientais, sociais e econômicos" (LIMA et al., 2017). Sendo assim, a discussão sobre a valorização dos solos na educação formal e informal é uma grande oportunidade para a conscientização ambiental, visto que, existem diversos recursos e abordagens pedagógicas que podem ser utilizados para melhorar o ensino da educação ambiental, salientando a importância da conservação do solo (GUIMARÃES et al., 2012).

Posto isso, a proposta da oficina teve como objetivo contextualizar os conceitos sobre os tipos de solo e a importância desse recurso natural para os indígenas, a fim de incentivar os alunos não indígenas do ensino fundamental a compreenderem a relevância da preservação do solo, a valorização deste meio e o fazer bom uso dele. Portanto, "a melhoria da qualidade do ensino de solos no Nível Fundamental poderia aumentar a consciência ambiental dos estudantes em relação a este recurso natural, o que não resolve o problema da degradação, mas seria mais uma contribuição para a reversão deste processo" (SANCHEZ et al., 2010). Assim, a educação estará a serviço da transformação social a partir da abordagem contextualizada dos conteúdos histórico-científicos (LIBÂNEO, 1986).

Considerando que "é sobre os solos que as sociedades constroem suas moradias, retiram seus alimentos, trabalham e travam suas lutas, além de ser por ele que passa boa parte dos resíduos advindos das atividades humanas" (CUNHA et al., 2015), o estudo sobre o solo está vinculado com a base de sustentação do modo de vida da sociedade. Isto posto, abordamos a utilização do solo como meio de sobrevivência não só os povos indígenas, mas toda a humanidade, e na abordagem em sala de aula, tal conteúdo tende a impactar aos alunos diante da grande relevância para a vida humana desse recurso natural, especialmente nas culturas indígenas cuja subsistência se concentra no cultivo de alimentos, na caça e na pesca.

Por conseguinte, a proposta da oficina partiu da necessidade de discutir a preservação dos solos, tendo em vista que muitos se preocupam apenas em preservar a água e as florestas e acabam se esquecendo da grande importância de preservar o solo. Desse modo, fez-se necessário problematizar e contextualizar os conteúdos relacionados com a importância do solo, com foco principal para sua utilização pelos povos indígenas, sendo que esse é o principal recurso para a agricultura, a produção de alimentos, utensílios e artesanatos para este povo. 
A partir desta temática, de forma prática e dinâmica, abordou-se sobre os tipos de solos, sua importância e meios de preservação e sua utilização pelos indígenas, além de se discutir sobre a diversidade e valorização cultural, a necessidade social do respeito às diversidades étnico-raciais, fomentando a conscientização a respeito das variedades culturais que abrangem o nosso país. Além disso, para a realização da oficina, foram desenvolvidos experimentos de germinação de sementes e infiltração de água no solo.

\section{METODOLOGIA}

\section{A realização da oficina pedagógica}

A oficina foi realizada no dia 20 de Março de 2018 no Grupo Escolar José da Silva Nazário, localizada no município de Campo Formoso, no povoado de Poços, na qual foi aplicada na turma do $4^{\circ}$ Ano do ensino fundamental, que era constituída por 25 alunos com faixa etária de 9 a 10 anos de idade.

Para a execução da oficina pedagógica se utilizou de três recursos, sendo eles teóricos, expositivos e práticos. No primeiro momento, foi realizado a abordagem do tema, explicando sobre os diferentes tipos de solo, sua importância e meios de preservação, e explanado a respeito do histórico sobre os indígenas e a grande importância desse recurso natural para os mesmos. Sendo assim, como método expositivo foram levadas amostras dos tipos de solo (arenoso, argiloso, calcário e humoso), alimentos, utensílios e artesanatos produzidos através do solo de forma direta e indireta.

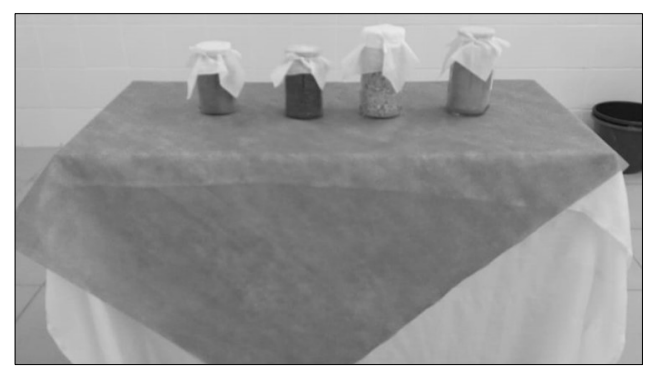

Imagem 1: Amostras com solo.

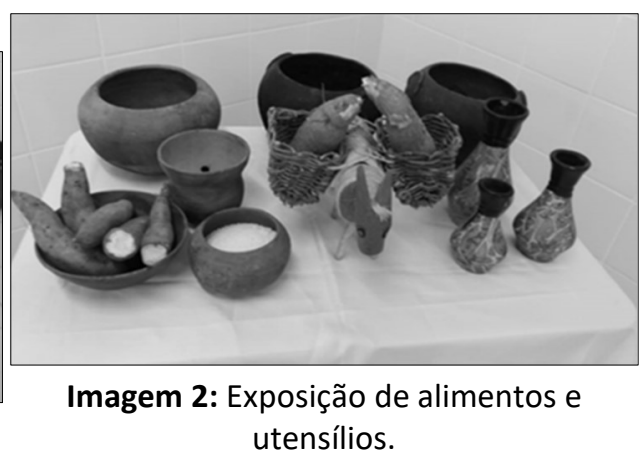

utensílios.

Em seguida, junto com os(as) alunos(as) foi realizado um experimento com a utilização de garrafa pets para demonstrar como ocorre a infiltração em dois tipos de solos, neste caso utilizando o arenoso e o argiloso, identificando qual possuía maior capacidade para o cultivo.

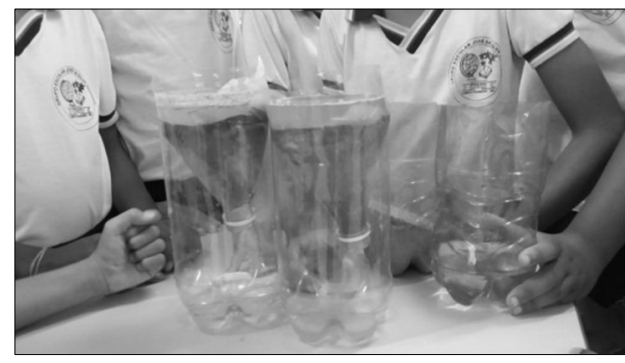

Imagem 3: Experimento.

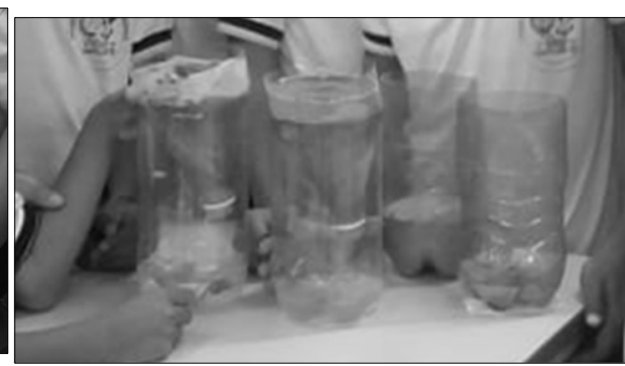

Imagem 4: Experimento.

Este experimento serviu de base para a execução da próxima prática, no qual cada aluno realizou o plantio de sementes de feijão, tendo a responsabilidade de levar para casa e acompanhar a germinação e o 
desenvolvimento dessa cultura. Para finalizar a oficina, foram distribuídas folhas de oficio para toda a turma de forma que pudesse expressar tudo o que foi absorvido em cada momento da oficina.

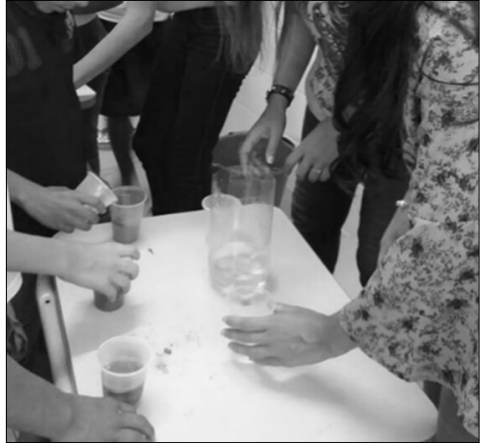

Imagem 5: Plantio de sementes.

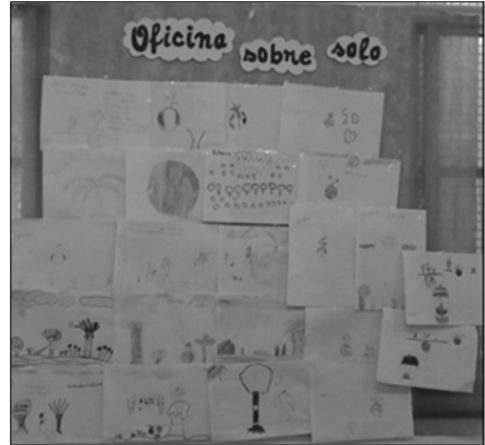

Imagem 6: Painel das atividades.

\section{RESULTADOS E DISCUSSÃO}

Mediante a aplicação da oficina foi notório perceber uma grande interação dos alunos em todas as atividades realizadas, tendo em vista que se trata de um tema que thes despertou curiosidade. Por conseguinte, observou-se gradualmente durante as atividades que os alunos reconstruíram o seu conceito de solo, e a partir da oficina tiveram uma nova visão da importância da preservação deste recurso natural para a vida humana e principalmente, os alunos compreenderam a interdisciplinaridade entre as ciências naturais e a história dos povos indígenas. Nesse sentido, os discentes partiram daquilo que conheciam e a partir dos conhecimentos historicamente acumulados pela humanidade (SAVIANI, 2009), avançaram na compreensão da realidade e na sua possível transformação.

Diante disso, foi perceptível que todo conteúdo apresentado foi assimilado de forma positiva por todos os alunos, alguns já apresentaram conhecimento transformado sobre a temática. Dessa maneira, Muggler et al. (2006), fundamentam que a educação é caracterizada como um instrumento na construção de valores, condutas e atitudes, sendo assim, discutir em sala de aula sobre o estudo do solo de maneira contextualizada e problematizadora, é imprescindível para a formação de pessoas conscientizadas ambientalmente.

\section{CONCLUSÕES}

A aplicação da oficina na classe de alunos não indígenas se fez muito importante, pois, além da discussão dialógica e expositiva sobre os tipos de solo e sua importância, assim como os meios de preservação, possibilitou aos estudantes um conhecimento maior sobre a cultura indígena, o que permitiu uma abordagem interétnico e intercultural através do conteúdo abordado.

Assim, a oficina se cumpriu com a indissociabilidade entre saberes e práticas. Na qual, os alunos se sentiram motivados em cultivar e preservar o solo, como também respeitar e valorizar a cultura indígena.

Com base nas pesquisas desenvolvidas foi possível analisar não só a importância do solo para os indígenas, mas a relevância da inclusão educacional e social, buscando criar um espaço de convivência escolar 
que possa trabalhar e estabelecer relações entre a realidade desses alunos e do povo indígena, conhecendo não só as diferenças, mas elementos indígenas em suas práticas cotidianas.

\section{REFERÊNCIAS}

CUNHA, J. E.; ROCHA, A. S.; TIZ, G. J.; MARTINS, V. M.. Práticas pedagógicas para ensino sobre solos: aplicação à preservação ambiental. Terra e Didática, Campinas, v.9, n.2, p.74-81, 2015. DOI: http://doi.org/10.20396/td.v9i2.8637395

GUIMARÃES, H. M. A.; CRISTO, S. S. V.; PAIXÃO, R. B.; SANTIAGO, A. M. A.. Educação ambiental: nossos solos, nossa vida. Educação Ambiental em Ação, v.9, n.41, 2012.

LIBÂNEO, J. C.. Democratização da escola pública: a pedagogia crítico-social dos conteúdos. São Paulo: Loyola, 1986.

LIMA, M. R.; VEZZANI, F. M.. Desenvolvendo a educação ambiental articulada à temática do solo. In: ENCONTRO
PARANAENSE DE EDUCAÇÃO AMBIENTAL, 14. Anais. 2017. p.1-4.

MUGGLER, C. C.; PINTO SOBRINHO, F. A.; MACHADO, V. A.. Seção VII - Ensino da ciência do solo: educação em solos: princípios, teoria e métodos. Revista Brasileira de Ciência do Solo, v.30, n.4, p.733-740, 2006.

SANCHEZ, S. B.; GUIMARÃES, L. D. D.. Solo vivo ou não vivo: mudando paradigmas. In: CONGRESSO BRASILEIRO DE GESTÃO AMBIENTAL, 1. Anais. Bauru, 2010. p.1-6.

SAVIANI, D.. Escola e democracia. 41 ed. Campinas: Autores Associados, 2009.

A CBPC - Companhia Brasileira de Produção Científica (CNPJ: 11.221.422/0001-03) detém os direitos materiais desta publicação. Os direitos referem-se à publicação do trabalho em qualquer parte do mundo, incluindo os direitos às renovações, expansões e disseminações da contribuição, bem como outros direitos subsidiários. Todos os trabalhos publicados eletronicamente poderão posteriormente ser publicados em coletâneas impressas sob coordenação da Sapientiae Publishing, da Companhia Brasileira de Produção Científica e seus parceiros autorizados. Os (as) autores (as) preservam os direitos autorais, mas não têm permissão para a publicação da contribuição em outro meio, impresso ou digital, em português ou em tradução. 